\title{
Realization Paths and Analyzing of Research Feedback Teaching in local Universities
}

\author{
Zhiguo Sun ${ }^{1, *}$, Li Zhang ${ }^{1}$ \\ ${ }^{1}$ School of Environmental and Materials Engineering, Shanghai Polytechnic University, Shanghai 201209, China, \\ *Corresponding author. Email: zgsun@sspu.edu.cn
}

\begin{abstract}
It has always been considered that paying equal attention to teaching and scientific research is the basic characteristics of the modern university. The function of research feedback teaching is increasingly prominent. This article is based on the condition of local universities. It analyses the connotation of research feedback teaching, and discusses the realization path of research feedback teaching.
\end{abstract}

Keywords: scientific research, teaching, connotation, realization path

\section{CONNOTATION OF RESEARCH FEEDBACK TEACHING}

\subsection{Teaching and scientific research are unified in the cultivation of applied talents}

Recent studies also show that scientific research and teaching should be unified to develop, and they should promote each other. Firstly, the research results show that scientific research can promote the practice of teaching. In the process of scientific research, teachers need to consult literature, visit experts, enrich their own knowledge, and enrich their teaching content to promote the practice of teaching. Teachers' scientific research activities can promote students' innovative practice in the process of learning. Students learn the methods of thinking and analysing the problems while they follow the teachers to do the research, and enhance the understanding of theories in the process of practicing, which builds a bridge of communication for study and employment. Besides, it can also improve teachers' ability of guiding students' scientific research.

Secondly, it is not the only purpose of teaching to disseminate and acquire the knowledge. It has been part of scientific research that teachers and students find the new problems, think and explore the problems in the process of teaching. Thus teaching produces positive imputes to scientific research. Teaching can not only provide content and direction of research for scientific research, but also deliver the research methods, so that scientific research can be carried out continuously and effectively ${ }^{[1]}$.

\subsection{Constructing the teaching model of student- centered and students' self-regulated learning}

In traditional teaching, teachers play an active role in the whole teaching activities, and students just accept it passively. So it is difficult to arouse the learning enthusiasm of teaching actively. It is necessary to introduce the relevant research results and the cuttingedge problems to teach selectively in the form of teaching cases. They may promote the connotation of teaching constantly to make teaching and scientific research integration and improve each other. It not only strengthens students' understanding of theoretical knowledge, but also helps students understand the research frontier of their subject. It arouses students' interest in learning, and promotes the interaction and the communication between teachers and students.

\subsection{Scientific research should be rooted in applied research or applied basic research}

Scientific research should be rooted in "cooperation between schools and enterprise, Integration of industry and education". As a local university, it is necessary to do well in the applied research and solve the practice problems for the enterprise. To find the problems from the practice of enterprise, and combine the research frontier of their subjects to solve problems. Finally, this process can be raised to theories and will feed the teaching in turn. Such scientific research is a better 
feedback and support for teaching. The scientific research of applied universities should be rooted in the local demand. The scientific research of applied universities should select subject from local practice, and the results of research should be applied to the local areas. ${ }^{[2]}$

\section{EXPLORING OF THE REALIZING PATH OF RESEARCH FEEDBACK TEACHING}

\subsection{Progress of latest scientific research enriches the classroom's content and realizes the source of teaching.}

The innovation and advancement of scientific research results determine that its research content represents the latest research progress in the fields of various disciplines. Textbook is difficult to reflect the latest research development of a certain science and technology in a comprehensive and timely manner because of the relative lag of time that compared with the actual development trend of scientific research. This lag has become a major problem affecting the substantial progress of higher education reform. While carrying out scientific research, teachers must keep up with the development research frontier, follow the new trend of the development of science and technology in time, enrich their own knowledge, and improve their knowledge structure. According to their own research characteristics and advantages, if teachers reflect the latest scientific research achievements, it will not only link teaching and scientific research closely, but also speeds up the updating of theoretical teaching contents and satisfies the students' vigorous desire for knowledge, which may make up the shortcomings of the textbook in a certain extent ${ }^{[3]}$

\subsection{Cultivating students' innovative thinking and ability through teacher-student interaction and two-way communication}

Integrating the spirit of scientific research into the concept of education. Innovation is the most essential work of scientific research is innovation, not mechanical repetition and imitation. The process of teachers' participation in scientific research is also a process of forming and cultivating the spirit of scientific research, which is favour to cultivate teachers' ability of analysing and solving problems and creative thinking. In the process of teaching, teachers teach their own engaging experience in scientific research to students by words and deeds through classroom's discussion, case analysis, etc. It is beneficial to cultivate students' spirit of scientific research of exploring knowledge and criticizing innovation, to stimulate their interest, to active their thinking, to improve their practical ability to analysis and solve problem. Students are encouraged to dare to criticize and query, to express independent opinions, and to continuously improve students' innovative thinking and ability through interactive communication.

\subsection{Relying on the advantages of scientific research resources, establishing a scientific research practice system and strengthening the construction of practice bases}

Establishing the practice system of scientific research should be carried out from the following aspects: Firstly, all scientific research projects should be open to college students to satisfy the dual desire of some students for knowledge and innovation. Secondly, setting up practice groups of teachers and students through the method of mutual selection. Furthermore, realizing the seamless connection between teachers' scientific research and students' extracurricular science and technology activities. Students can participate in some or all of the teacher's work, incubate and generate all kinds of scientific research competitions ${ }^{[4]}$. The school can use college students' system of assistant scientific research and the system of technological innovation bases, and establish a perfect system of all kinds of extracurricular science and technology activities. Bringing scientific research into the relevant contents of experimental teaching through the organic combination of scientific research and experimental teaching, it can cultivate students' innovative spirit and practical ability effectively.

The cultivation of innovative and applied talents in local colleges and universities can't be separated from the participation of enterprises. Through the cooperation of schools and enterprises, students can adapt to the needs of local economic and social development more quickly. First of all, local colleges and universities should cooperate with enterprises to set up enterprise training base and build practical training platform for cultivating applied talents; secondly, they should expand innovative and practical platform, and attract enterprises to participate in the construction of platform, and create a simulated practice environment for students. Through the cooperation of school and enterprise, enterprises can choose the talents which are needed for development, and colleges and universities can reap the results of cultivation of applied talents and realize the win-win cooperation mode between universities and enterprises.

\subsection{Establishing a system of opening all scientific research projects to students, and realizing the connection between scientific research activities and knowledge learning}

It can be considered from two aspects: Firstly, some students who has strong scientific research ability and belongs to the tight type can directly enter the scientific research group to carry out their work. Secondly, the majority of students who belongs to the auxiliary 
participation type can participate in it by the methods of literature research, data collation, discussing, and so on ${ }^{[4]}$. At present, many teachers in universities have their own scientific research projects, and they can explore all scientific research projects to open to college students, and it can not only solve the problem of funding for students' scientific research projects, but also allow students to undertake part of the scientific research work. In the scientific research activities, the students who are the main body have high enthusiasm, and they study the methods of consulting and reading the literature, and acquire certain experimental skills. They can apply the theory to the experiment, and obtain the improvement of the scientific research ability. To cultivate students' creative consciousness and the ability of acquiring knowledge, that is, "to teach people to fish, not to teach people to fish", which has realized the connection between scientific research activities and knowledge learning.

\subsection{Reformation and reconstruction of graduation design}

Graduation design (thesis) is an indispensable practical teaching link in colleges and universities. To carry out the work in the process of reforming and perfecting graduation design (thesis), and introduce the whole process of education into the cultivation and management of students, and concern about students' growth and development. According the discipline advantage, it is necessary to establish the selection mechanism of the preparatory subject based on that the college students participate in research project of teacher, and their graduation project topic is formed. The undergraduates can join the teachers' research team in advance (first in the second year of undergraduate course) and participate in the research and practice of the teachers' research projects, and cultivate the spirit of cooperation in the team, and prepare for the graduation design (thesis) after completing their basic course. Establishing a management model of management, supervision and evaluation to make the graduation design (thesis) process form a closed loop, so as to achieve the role of graduation design (thesis) in the whole teaching process, that is, to consolidate, deepen, and expend the basic theories and professional knowledge. To make it systematize and synthesize, and cultivate students' practical ability, entrepreneurial ability and innovation ability. By introducing the reform and practice of undergraduate students' participation of research projects, they can improve the level of students' graduation design (thesis) from the process to the result, and explore new ways for the cultivation of applied undergraduate students' knowledge level and technical ability ${ }^{[5]}$.

\subsection{Scientific research's important support to college students' innovation activities, competitions and entrepreneurship}

In order to promote the feedback, to cultivate students' interest in their major, and satisfy their curiosity, and innovate the training mode of talents actively, we can organize and carry out energy-saving material innovation practice group, environmental pollution control innovation practice group, environment and materials engineering institute innovation talent group, university student science and technology activity association and so on. Selecting excellent students of different specialties in the whole school and cooperating with perfect elimination and exit mechanism. Using basic training, special research, system design and other research-based teaching methods to strengthen the training process. With the starting point of solving practical engineering problems, under the guidance of professional tutor, taking the students as the main body, through the comprehensive system of scientific research training and practice, the students can master the practical skills and thinking methods of scientific research in a certain extent. Improve students' ability to solve problems independently. Students' innovative practical ability and engineering quality have been significantly improved by carrying out the inquiry learning which closely combines engineering practice $^{[6]}$.

\section{CONCLUSION}

The connotation of research feedback teaching were stated and summarized. Moreover, the realization paths of research feedback teaching for local universities have been discussed and analysed.

\section{REFERENCES}

[1] Z. Shi, Y. Wang. Current situation of the university teachers research feedback teaching and analysis of influencing factor. Higher Education Review. 2016, pp.119-129.

[2] Z. Wu, Q. Zhou, X. Wang. Realization approaches of research feeding teaching. Journal of Yichun College. 2011, pp.170-171.

[3] Q. Wu. How to improve the scientific research innovation of college students. Education Teaching Forum. 2012, pp.12-13.

[4] C. Li, W. Feng. Implement of research feeding teaching for universities. Research of Education Development. 2015, pp.109-110.

[5] X. Wang, C. Qian. Problem and solution of research feeding teaching for local universities. Journal of Kaifeng Institute of Education. 2015, pp.109-110.

[6] W. Xiang, H. Su. Study and practice of research feeding teaching. West China Development. 2013, pp.59-60. 